\title{
Influence of Inlet Position on the Amount of Pollutant Particles Trapped Along the Flow Path of Slow Sand Filter (SSF) Pipe Utilized for Filtering Swamp Water
}

\section{Sigit Mujiharjo , Syafnil, and Ilma Donna Astri Harahap}

Departement of Agricultural Technology, Faculty of Agriculture, University of Bengkulu ${ }^{*}$ Email address : Sigitmujiharjo@aol.com

\begin{abstract}
This study aims to explain the effect of inlet position ofa Slow Sand Filter (SSF) Pipe on the amount of pollutant particles caught along the flow path in the SSF Pipe. The main equipment used is nine pieces of SSFPipe, each has 4 inches in diameter and 50cmin length with Pantai Panjang Bengkulu's sand as the filter medium. The inlet positions tested were $90^{\circ}, 45^{\circ}$ and $0^{\circ}$; repeated three times and arranged in a Completely Randomized Design (CRD). The observed variable is the weight of the captured pollutant in the SSF at the distance of $10 \mathrm{~cm}, 20 \mathrm{~cm}, 30 \mathrm{~cm}$, and $40 \mathrm{~cm}$ from the inlet. Results of the research showed that the number of pollutant particles caught the inletwas increased. The number of pollutant particles caught also decreased with the decrease of inlet position slope. The inlet position significantly affected the number of pollutant particles caught along the flow path; the position of $90^{\circ}$ causes the highest amount of pollutants to be caught and significantly differs from that of the position of $45^{\circ}$ and $0^{\circ}$. Position of $0^{\circ}$ causes the least amount of pollutants to be captured that considered to be the best inlet position so far. It is important; however, to research whetherinlet position of more than $180^{\circ}$ could result in much smaller amount of pollutant caught along the flow in the SSFPipe.
\end{abstract}

Keywords: SSFPipe, inlet position, particle caught in SSF, peat water filtration

Citation to this paper should be made as follows :

Mujiharjo, S., Syafnil, and I.D.A. Harahap. 2018. Influence of Inlet Position on the Amount of Pollutant Particles Trapped along the Flow Path of Slow Sand Filter (SSF) Pipe Utilized for Filtering Swamp Water. Agritropica: Journal of Agricultural Science. 1 (1): 47-55. DOI:

https://doi.org/10.31186/J.Agritropica.1.1.47-55

\section{INTRODUCTION}

People living in swamp areas have difficulties in having clean water to meet their daily needs. Water obtained from dug wells in swamp areas is generally brownish in color as they contain decaying organic substances such as humus, planton, iron as well as manganese (Syarfi, 2007). The presence of these substances cause the swamp water does not meet the requirements for clean nondrinking water. In terms of quantity, swamp water may potentially be used as a source of household water; considering the abundance. One easy and inexpensive effort to improve swamp water quality is to filter it using sand medium.
Sand filter is an old and very simple water treatment technology to produce good quality clean water. Particles of sand form pores that able to separate solidsand suspended pollutants from liquid. Sand filter is also effective in changing the chemical and biological properties of filtered water. Results of Saeni (1986) research showed that sand filter is able to reduce water turbidity level from 12.122.5 ppm to 3.0-5.5 ppm; while Mujiharjo (1998) reports that fine sand filter is capable of separating more than $90 \%$ of suspended solids from the liquid. Moreover, Mujiharjo et al. (2004); Unger and Collins (2008) also reported that fine sand filter is able to reduce E. Coli 
contaminating water. Furthermore, Gottinger et al (2011) stated that "The flexible and modular design options inherent to SSF systems, along with the modifications in expanded application, make SSFs highly attractive for potable water treatment in rural and remote regions".Sand filter employing fine sand as the filter medium is well known as slow sand filter (SSF).

Slow sand filter (SFF) Pipe is a slow sand filter where fine sand functioning as the filter medium is placed in a pipe. It is divided into circling layers by thin plate of aluminum. The water to be filtered enters to the filter through small holes along the length of the main pipe, flows into filter medium following the circlingflow guide, and exits through the small holes along the length of the outlet (small) pipe located at the center of the main pipe (Mujiharjo, 2010). Advantages of SSF Pipes are, in addition to low-cost and simpletechnology manufacturing, small in size so that it is portable and easy to care. On the other hand, one disadvantage is that it requires an extra careful in constructing; especially when incorporating fine sand as a filter medium into the pipe (Mujiharjo, 2011).

Mujiharjo et al. (2012) built and tested SSF Pipe with inlet position perpendicular to the basin to reduce color, turbidity, TSS and odor of rubber industryliquid waste with respect to hydraulics head. Result of the research showed that SSF Pipe was able to decrease color from brown to colorless; turbidity from 204 NTU to 4.33 NTU; TSS from $264 \mathrm{mg} / \mathrm{L}$ to $15.33 \mathrm{mg} / \mathrm{L}$; odor from very smelly becomes somewhat smelly. In general, it is concluded that the performance of a SSF Pipe in separating pollutant of liquid waste is satisfactory; however, the filtration rate decreases much faster than that of the standard SSF.This fact is believed to be caused by inappropriate installation of the inlet position.

Installation of SSF Pipe with the inlet position of $90^{\circ}$ is thought to cause more particles pollutant enters and is captured in the SSFPipe medium as the inlet holes are facing upwards that ease and direct particles pollutant in the filtrate enter to the SSF, or accumulate on the inlet holes. Presence of organic pollutant on the inlet of SSF Pipe is expected as it could stimulate colonies of good microorganisms to live and assist screening pollutants by forming layer called schmutzdeckeor hypogeal (Huisman, 1994); but if it is too much it could hinder the filtering process. Therefore, inlet position of SSF Pipe other than $90^{\circ}$ could probably improve the SSF Pipe performance that could be used to help people living in swampy area to have clean water to fulfill they daily water need. This study aims to explain the effect of inlet position of SSFPipe on the number of pollutant particles caught along the flow path in SSF Pipe used to filter swamp water and to find the best inlet position that could be produce standard household clean water quality.

\section{RESEARCH METHODS}

\section{Equipment and Experiment Design}

The main equipment used in this research is nine units Slow Sand Filter (SSF) Pipe, each has 4 inches in diameter and $50 \mathrm{~cm}$ in length; complementary of SSF Pipe in the form of plastic tubs measuring $65 \mathrm{~cm} \times 50 \mathrm{~cm} \times$ $45 \mathrm{~cm}$ as many as 9 units, two meter in length and 0.5 inch in diameter plastic tube as many as 9 units; 0.5 inch inverting flow control valve for 9 units; and a 100 liter container.

The materials for the SSF Pipe medium was fine sand found from PantaiPanjang beach in Bengkulu. The fine sand selected was the one transported by wind erosion deposited around $10 \mathrm{~m}$ from the tidal area; to have the relatively pure fine sand that free fromcontaminant particles.

This study was conducted following a completely randomized design (CRD) with the inlet position as the main treatment consisting of $0^{\circ}(\mathrm{P} 1), 45^{\circ}(\mathrm{P} 2)$ and $90^{\circ}(\mathrm{P} 3)$; each of them was repeated three times so that there were 
nine experimental units. The result of randomization of the experimental unit's place order was P2(1), P3(2), P2(2), P1(3), P3(1), P2(3), $\mathrm{P} 1(1), \mathrm{P} 3(3)$, and P1(2).

\section{Setting the SSF Pipe and Main Equipment}

SSFPipes used in this study are uniform in shape and internal measurement size; aremade from PVC pipe as the frame, have 4 inch in diameter and $50 \mathrm{~cm}$ in lengthconstructed based on Mujiharjo (2010). Before installation, a sample of $7.4 \mathrm{ml}$ from each of SSF Pipe medium wascollected, dried out that no moisture in it, thenweighted as the initial weight of the SFF medium.

The first three randomly selected SSF were placed in three different plastic tubs having the same dimensions; each of them installed with inlet position of $0^{0}$ with the outlet pipe break through the plastic tubs wall so that the filtrate is able to flow out of the plastic tub through the SSF medium. Three other SSFs and the other remaining three SSFs, werealso placed on a different plastic tub that having the same dimensions as it was done for the first three;inlet position, however, were installed at $45^{\circ}$ for each of the second three; and at $90^{\circ}$ for each of the last three SSFPipes.

The nine plastic tubs each contains SSF Pipe, then placed on a flat bench with the squencefollowing the result of randomization. All plastic tub are connected to a temporary water reservoir using a 0.5 -inch plastic pipe equipped with flow control valves. The reservoir is placed on a flat bench with a higher elevation than that of the plastic tubs so that the filtrate could flow from the reservoir to the plastictubs.

\section{Filtering poses and sample collection}

All of the plastic tubswere then flooded with clear water by filling the reservoir with clear water and flushed it out to each of the SSF Pipe basin until full; allowed clear water to flow from the basinto enter the inlet of the SSF Pipe, to go along the medium and then to leavethe plastic tub through the SSF outlet pipe.
Flooding with clean water is intended to create SSFPipes preconditions and to have a stable and uniform filter mediumsettlement. The precondition process was terminated by emptying clean water from the container as well as from the basin.

Soon after the container empty, the reservoir was filled with the swamp water to be filtered. The swamp water was then flowed from the reservoir to the SSF basin until the swamp water surface was $30 \mathrm{~cm}$ above the upper surface of the SSF. The flow rate of swamp water entering the SSF basin is thus arranged so that the water level in the SSF tub remains $30 \mathrm{~cm}$ above the SSF. Drainage of swamp water through SSF Pipe was continuously diluted for 10 days to allow SSF Pipe to catch enough swamp water pollutants.

On the $11^{\text {th }}$ day there will be a cessation of the drainage process by emptying the swamp water either in the container basin or in the SSF basin. One by one the SSFwas removed from the plactictub, then opened the lid of the nonoutlet section to sample the sand mediumalong the flow path at the distance of $10 \mathrm{~cm}, 20 \mathrm{~cm}, 30$ $\mathrm{cm}$ and $40 \mathrm{~cm}$, each of $7.4 \mathrm{ml}$. The samples were then dried out that no moisture in it; and then weighted; to be recorded as the final weight of the SSF medium sample.

\section{Data analysis}

The number of particles caught in SSF Pipe was calculated as the difference between the weight of the final SSFmediumsample and the initial weight of the SSF medium sample. The results of calculationwere then tabulated according to the inlet position and distance from the inlet.

To achieve the first objective, the tabulated data on each inlet positionwere plotted in a Cartesian diagram, then analyzed by regression and correlation to find the most suitable equation for expressing the relationship between the number of pollutants caught by their distance from the inlet; which was then 
used to predict the flow distance from the inlet that produces the free from pollutantfiltrate.

To achieve the second goal, the number of particles caught in SSF Pipe with different inlet position but the same distance from the inlet, were analyzed their difference using ANOVA. If the difference was significant or very significant, then tested using Duncan's Multiple Range Test (DMRT) method at a significant level of $5 \%$.

\section{RESULTS AND DISCUSSION}

Particles Caught along the flow path in SSF Pipe with Inlet Position of $90^{\circ}$

Results of data calculation, the number of pollutant particles caught along the flow path in the SSF Pipes used to filter swamp water with inlet position of $90^{\circ}$ are presented in Table 1.

Table 1 Number of Particles Caught in SSF Pipe with Inlet Position of $90^{\circ}$

\begin{tabular}{ccccc}
\hline \multirow{2}{*}{ Replicate } & \multicolumn{4}{c}{ Captured Particles $\left(\mathrm{g} / \mathrm{dm}^{3}\right)$} \\
\cline { 2 - 5 } & $10 \mathrm{~cm}$ & $20 \mathrm{~cm}$ & $30 \mathrm{~cm}$ & $40 \mathrm{~cm}$ \\
\hline 1 & 9.850 & 9.565 & 8.763 & 8.540 \\
2 & 9.790 & 9.208 & 8.852 & 8.420 \\
3 & 9.820 & 9.325 & 8.870 & 8.440 \\
\hline Average & 9.820 & 9.366 & 8.828 & 8.467 \\
\hline
\end{tabular}

Table 1 shows that the farther the distance from the inlet the less number of particles is caught. Slow sand filtration process includes physical and mechanical process as well as biological process (Clark, et al, 2016; Itaca Water Treatment, 2015). The physical and mechanical process includes straining at the surface media; interception, diffusion, sedimentation, and hydrodynamic occurrence inside media that makes pollutants close to sand grain; attachment by the grains (Itaca Water Treatment, 2015). Therefore, the fact that the farther the less number pollutants trapped in the media is presumably because whenever swamp water entering through the inlet into the SSF Pipe medium, pollutants larger than the pores of medium would be retainedwhereas the smaller would continue to flow through the medium. Inside the medium, some of the pollutants would continue to flow farther toward the outlet and some others are absorbed or deposited on the sand surface. The presence of particles attached or bound by grains of sand could cause the pores getting tighter, so that the farther from the inlet would be fewer pollutants could be passed. Thus, the number of pollutants that colud reach a greater distance from the inlet would be less; so that the captured pollutants would also fewer.Plot of the number of particles captured along the flow path in SSF Pipe with inlet position of $90^{\circ}$ could be seen in Figure 1.

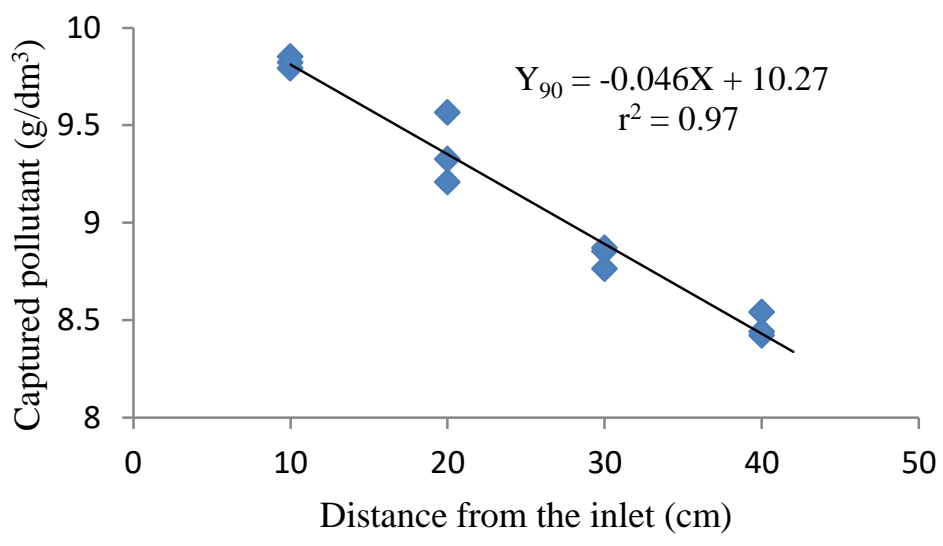

Figure 1 Plot of the Number of Particle Caught in the SSF Pipe for Inlet Position $90^{\circ}$

50 | Mujiharjo et al : Influence of Inlet Position on the Amount of Pollutant Particles Trapped along... 
Based on regression analysis, with the inlet position of $90^{\circ}$, it was found that the most suitable equation to express the relation between the number of pollutant captured $\left(\mathrm{Y}_{90}\right)$ with the distance from the inlet $(X)$ is by linear equation $\mathrm{Y}_{90}=-0.046 \mathrm{X}+10.27$ with $\mathrm{r}^{2}=0.97$. From the equation found, it could be predicted that the SSF Pipe with inlet position of $90^{\circ}$ would have filtratebeing free from pollutants if the distance from inlet to outlet is $223 \mathrm{~cm}$.

\section{Particles Caught in SSF Pipe with Inlet Position of $45^{\circ}$}

The results of data calculation of the number of pollutant particles caught along the flow path in the SSF Pipe used to filter swamp water with the inlet position of $45^{\circ}$ can be seen in Table 2.

Table 3 Number of particles Caught in SSFPipe with Inlet Position of $45^{0}$

\begin{tabular}{ccccc}
\hline \multirow{2}{*}{ Replicate } & \multicolumn{4}{c}{ Captured Particles $\left(\mathrm{g} / \mathrm{dm}^{3}\right)$} \\
\cline { 2 - 5 } & $10 \mathrm{~cm}$ & $20 \mathrm{~cm}$ & $30 \mathrm{~cm}$ & $40 \mathrm{~cm}$ \\
\hline 1 & 7.293 & 7.226 & 6.425 & 6.191 \\
2 & 7.115 & 6.879 & 6.336 & 6.178 \\
3 & 7.271 & 7.115 & 6.413 & 6.180 \\
\hline Average & 7.226 & 7.073 & 6.391 & 6.183 \\
\hline
\end{tabular}

It can be seen on Table 3 that the farther the distance from the inlet the less number of particles is caught; as it happens when the inlet position is $90^{\circ}$. From data on Table 3 could also be calculated, the reduction of the number of particles captured at each $1 \mathrm{~cm}$ farther increment is $0.038 \mathrm{~g} / \mathrm{dm}^{3}$; which means at a distance of $10 \mathrm{~cm}$ from the inlet the decrease of particles is $0.38 \mathrm{~g} / \mathrm{dm}^{3}$. This is presumably because as described in the previous subsection that during the filtration process pollutants larger than the pores of medium would be retainedwhereas the smaller would continue to flow through the medium. Inside the medium, some of the pollutants would continue to flow farther toward the outlet and some others are absorbed or deposited on the sand surface. The presence of particles attached or bound by grains of sand could cause the pores getting tighter, so that the farther from the inlet would be fewer pollutants could be passed. Thus, the number of pollutants that colud reach a greater distance from the inlet would be less; so that the captured pollutants would also fewer. Plot of the number of particles captured along the flow path in SSF Pipe with the inlet position of $45^{\circ}$ can be seen at Figure 2.

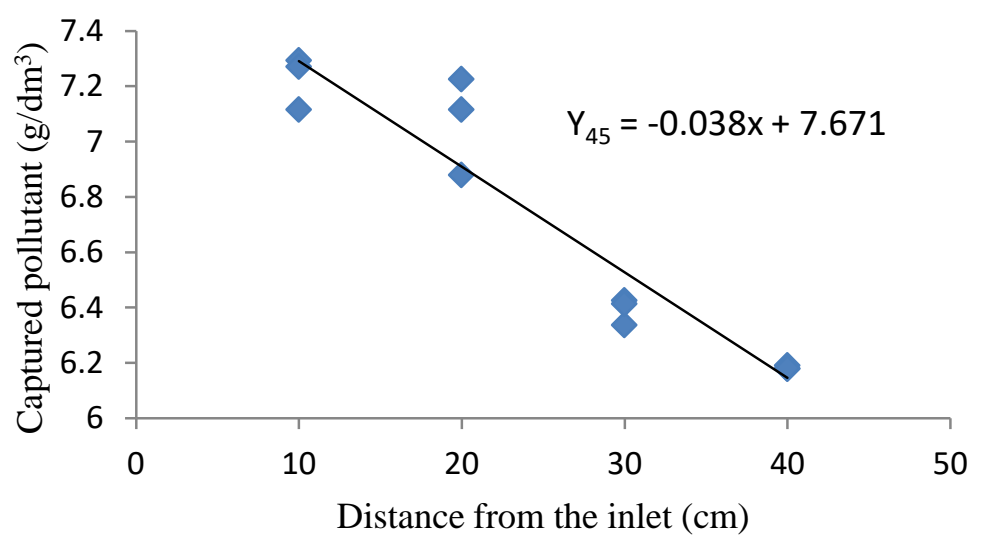

Figure 2. Plot of Particles Caught in SSF Pipe at Inlet Tilt $45^{\circ}$

Figure 2 shows that the decrease of the follows the equation of $Y_{45}=-0.038 x+7.671$ number of particles captured in SSF Pipe $\left(\mathrm{Y}_{45}\right)$ with $\mathrm{r}^{2}=0.901$. Based on that equation it can be with increasing distance from the inlet $(X)$; estimated that, at inlet position of $45^{\circ}$, the 
optimal flow distance to produce the swamp water filtrate free from pollutant particle is when the flow length between the inlet to the outlet is $201 \mathrm{~cm}$.

\section{Particles Caught in SSF Pipe with Inlet Tilt $0^{\circ}$}

The result of measured data calculation on the number of particles captured in the SSF Pipe used to filter swamp water with the inlet position of $0^{\circ}$ can be seen in Table 3 .

\section{Table 3. Amount of Particles Caught in SSF Pipe with Inlet Position of $0^{0}$}

\begin{tabular}{ccccc}
\hline \multirow{2}{*}{ Replicate } & \multicolumn{4}{c}{ Captured Particles $\left(\mathrm{g} / \mathrm{dm}^{3}\right)$} \\
\cline { 2 - 5 } & $10 \mathrm{~cm}$ & $20 \mathrm{~cm}$ & $30 \mathrm{~cm}$ & $40 \mathrm{~cm}$ \\
\hline 1 & 5.155 & 5.012 & 4.958 & 4.697 \\
2 & 5.149 & 5.000 & 4.773 & 4.543 \\
3 & 5.145 & 4.966 & 4.765 & 4.598 \\
\hline Average & 5.150 & 4.993 & 4.832 & 4.613 \\
\hline
\end{tabular}

From Table 3, it can be seen that generally the farther from the inlet the number of particles captured in the SSF is also reduced by an average reduction of $0.28 \mathrm{~g} / \mathrm{dm}^{3}$ per $10 \mathrm{~cm}$ distance. This is easy to understand because the filtrate water enters through the inlet hole so that at a distance closer to the inlet the number of particles is caught more. At the time of filtration process the pollutant coincides with the water passing through the pores of the sand, where particles that have larger sizes than the pores of sand will be retained in the pores of the sand; some smaller particles will be absorbed and deposited on the sand surface; others will continue to pass to a location farther from the inlet to the outlet. As the amount of pollutants the filtrate passes through the medium further away from the inlet, the smaller the pollutant can be captured by the medium than the inlet. Plot the number of particles captured in the SSF Pipe with the inlet $0^{\circ}$ slope position can be seen in Figure 3.

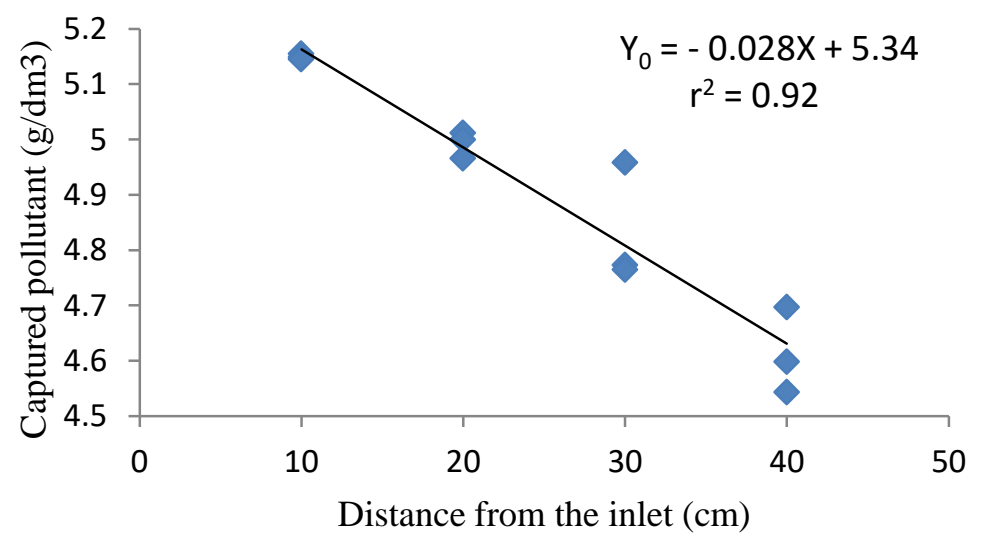

Figure 3 Plot of Particles Caught in the SSF Pipe with Inlet Position of $0^{0}$

Figure 3 presents seen that with the inlet slope position of $0^{0}$ the most suitable equation to express the relation between the number of particles caught in the SSF Pipe $\left(\mathrm{Y}_{0}\right)$ with the distance from the inlet $(\mathrm{X})$ is $\mathrm{Y}_{0}=.-0.028 \mathrm{X}+5.34$ with $\mathrm{r}^{2}=0.92$.
Based on the equation, it can be predicted that the flow distance in the SSF Pipe with an inlet position of $0^{\circ}$ that would produce filtrate free of pollutant particles is $190 \mathrm{~cm}$. 
Inlet Slope Link with Number of Particles Caught

Plot of the number of pollutants caught along the flow path in the SSF Pipe with the inlet position of $90^{\circ}, 45^{\circ}$ and $0^{\circ}$ can be seen in Figure 4. It can be seen at Figure 4 that the number of pollutants caught in the SSF Pipe with the inlet position $90^{\circ}$ is generally higher in number than that of the position of $45^{\circ}$ and the position of $0^{\circ}$. This is presumably because SSF Pipe with inlet position of $90^{\circ}$ is having inlet holesfacing upward; so the direction of pollutant precipitation is in the same direction of the flow; causing all pollutants to enter or accumulate on the surface of the SSF Pipe inlet. At the inlet position of $45^{\circ}$; however, the direction of flow is different from the direction of pollutants deposition; causing the pollutants partly follows the direction of the flow into the SSF or falls onto the inlet surface due to its non-flat surface (inclined $45^{\circ}$ ).

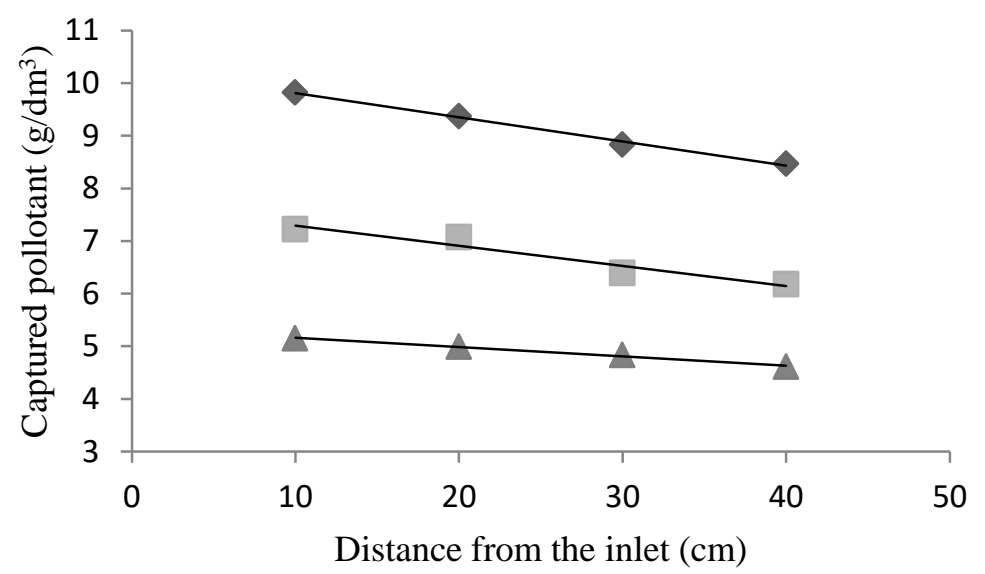

Figure 4 Plot of the amount of pollutant caught along the flow path in the SSF Pipe at various inlet position. $\triangle$ position of $0^{0}$; $\square$ position of $45^{\circ}$; $\triangleleft$ position of $90^{\circ}$

In the inlet position of $45^{\circ}$; in general, that enter into the SSF is less compared the number of particles captured is considerably compared to that of the inlet position of $0^{0}$. This is presumably because at the inlet position of $0^{0}$ the face of the inlet is perpendicular to the direction of pollutant deposition; so it is estimated that only the suspended pollutants enter into SSF Pipe; almost no pollutant settles on the inlet surface; so the number of pollutants

with that of the inlet position of $45^{\circ}$.

Results of variance analysis showed that the inlet position significantly affected the number of pollutants caught. This means that there is a significant difference in the number of captured pollutants if a SSF Pipe is operated with different inlet position. The average number of pollutants caught at various inlet position observed is presented in Table 5.

Table 5. Average Number of Pollutants Caught in SSF Pipe Operated at Various Inlet Position

\begin{tabular}{ccccc}
\hline \multirow{2}{*}{ Inlet Slope $(\mathrm{o})$} & \multicolumn{4}{c}{ Particles Caught $(\mathrm{g} / \mathrm{dm} 3)$} \\
\cline { 2 - 5 } & $10 \mathrm{~cm}$ & $20 \mathrm{~cm}$ & $30 \mathrm{~cm}$ & $40 \mathrm{~cm}$ \\
\hline $90^{\circ}$ & $9.820^{\mathrm{a}}$ & $9.366^{\mathrm{d}}$ & $8.828 \mathrm{~g}$ & $8.466^{\mathrm{j}}$ \\
$45^{\mathrm{o}}$ & $7.226^{\mathrm{b}}$ & $7.073^{\mathrm{e}}$ & $6.391^{\mathrm{h}}$ & $6.183^{\mathrm{k}}$ \\
$0^{\circ}$ & $5.149^{\mathrm{c}}$ & $4.992^{\mathrm{f}}$ & $4.832^{\mathrm{i}}$ & $4.612^{\mathrm{l}}$ \\
\hline
\end{tabular}

Note: numbers in a same column followed by different letters show a real difference

Based on Table 5, the number of pollutant particles caught at a same distance from the inlet for different inlet position significantly differ one to another. 
At the distance of $10 \mathrm{~cm}$ from the inlet with the inlet position of $0^{0}$, the average amount of pollutant captured in the SSF is 5.149 $\mathrm{g} / \mathrm{dm} 3$; which is fewer and significantly differsfrom that of the inlet position 0 f $45^{\circ}$; moreover from that of the inlet position of $90^{\circ}$. The same pattern is also shown for the distance from the inlet $20 \mathrm{~cm}, 30 \mathrm{~cm}$ and 40 $\mathrm{cm}$; which leads to the conclusion that the operation of SSF Pipe with the inlet position of $0^{0}$ would cause the amount of pollutant entering the SSF is less that would increase its service duration and economical life.

\section{CONCLUSION}

The number of pollutant particles caught along the flow path in the SSF Pipe decreases following a linear patternas the distance getting farther from the inlet. The rate of decline also decreases as the inlet position getting smaller.

Inlet positionof SSF Pipe significantly affects the number of pollutant particles caught along the flow path; the position of $90^{\circ}$ causes the highest number of pollutants to be caught and significantly differ from that of the $45^{\circ}$ or $0^{\circ}$. Inlet position 0 ; on the other hand, causes the least amount of pollutants to be captured; so that it is considered as the best inlet position so far. To have the really best inlet position; it is important to research whether aninlet position of more than $180^{\circ}$ could result in much smaller amount of pollutant caught along the flow in the SSF Pipe.

\section{REFERENCES}

Clark, P.A., C.A. Pinedo, M. Fadus, and S. Capuzzi. 2012. Slow-sand water filter: Design, implementation, accessibility and sustainability in developing countries. Med Sci Monit. 2012; 18(7): RA105RA117doi: 10.12659/MSM.883200

Gottinger, A.M, D.W. McMartin, D. Price, and B. Hanson. 2011. The effectiveness of slow sand filters to treat Canadian rural prairie water.Canadian Journal of Civil Engineering, 2011, 38(4):455463, https:/ / doi.org/10.1139/111018

http://www.nrcresearchpress.com /doi/abs/10.1139/111-

018\#.WwKe9EiFPIU. May 21, 2018.

Huisman, L. 1994. Slow Sand Filtration, Lecture Notes, IHE Delft Netherlands.

Itaca Water Treatment. 2015. An Introduction to Slow Sand Filtration.

http://www.solutionsforwater.org /wpcontent/uploads/2011/12/SlowSand-Filtration-Introduction-7-MB16-Dec-2011.pdf. May 21, 2018.

Mujiharjo, S. 1998. Effectiveness Test on Vertical Coastal Sand Filter to Remove Suspended Solids. Proc. of the Univ. of Bengkulu Research Bureau's Research Products. Bengkulu, October, 1998, 02:131-136.

Mujiharjo, S., Budiyanto dan Syafnil. 2004. Designed and Tested of Coastal Sand-Media Slow Sand Filter (SSF) to Improve the Quality of Water Sources Used in Tofu Industry in Bengkulu and Its Effects on the Process Production and Tofu Quality. Unpublished Research Report of SP-4 Program. University of Bengkulu.

Mujiharjo, S. 2010. Construction Steps and Operating Installation of a Pipe Slow Sand Filter (SSF).Unpublished Manuscript.

Mujiharjo, S. 2011. Notes to be Aware in Constructing a Slow Sand Filter Pipe.Unpublish Manuscript.

Mujiharjo, S., B. Sidebang and D.Darmadi. 2012. Performance of a Pipe Slow

54 | Mujiharjo et al : Influence of Inlet Position on the Amount of Pollutant Particles Trapped along... 
Sand Filter (ssf-p)with Difference Hydraulic Headson Filtering Pollutants of Crum rubber Plant Liquid Waste. J. Agroindustri, 2(2):77-83.

Saeni, M. S. 1986. Kemampuan Saringan Pasir, Ijuk, dan Arang dalam Meningkatkan Kualitas Fisika dan Kimia Air DAS Ciliwung. Thesis. Fakultas Pascasarjana IPB. Bogor.
Syarfi, 2007. Rejeksi Zat Organik Air Rawa dengan Membran Ultrafiltrasi; Jurnal Sain dan Teknologi [ 2 Februari 2011].

Unger, M. and M.R. Collins. 2008. Assessing Escherichia coli Removal in the Schmutzdecke of Slow-Rate Biofilters. J. American Water Works Association, 100 (12): 60-73. 